\title{
A Rationalized Overview of Diabetic Nephropathy
}

\author{
Dr. Lalita Bansal ${ }^{1 *}$, Dr. Ashish Dhiman ${ }^{2}$ \\ ${ }^{1}$ Medical Officer (OBG) R.H. Kullu Himachal Pradsh, India \\ ${ }^{2}$ Medical Officer (General Surgery), R.H. Kullu Himachal Pradsh, India
}

\section{Article History \\ Received: 17.11.2021 \\ Accepted: 14.01.2022 \\ Published: 21.01.2022}

Journal homepage:

https://www.easpublisher.com

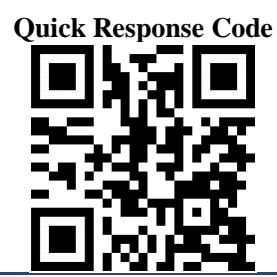

\begin{abstract}
Diabetic nephropathy is a prime motive of end-level renal disease, and there was a non-stop boom in its occurrence global with inside the beyond decades. Diabetic nephropathy is characterized via way of means of microalbuminuria, renal and glomerular hypertrophy, mesangial growth with glomerular basement membrane thickening, arteriolar hyalinosis, and international glomerular sclerosis, which in the long run motive the development of proteinuria and renal failure. The time period diabetic kidney disease (DKD) is now normally used to embody the spectrum of human beings with diabetes who've both albuminuria and discounts in renal function. In this article, the medical presentation and method to prognosis of DKD might be discussed, as will its prognosis. The popular ideas of control of DKD can also be reviewed close to modern-day global guidelines. The present review deal with brief about DN pathophysiology, prevention measures along with treatment approaches.

Keywords: Diabetic Nephropathy (DN), Diagnosis, prevention \& treatment.
\end{abstract}

Copyright (C) 2022 The Author(s): This is an open-access article distributed under the terms of the Creative Commons Attribution 4.0 International License (CC BY-NC 4.0) which permits unrestricted use, distribution, and reproduction in any medium for non-commercial use provided the original author and source are credited.

\section{INTRODUCTION}

Diabetic nephropathy (DN) refers to a feature set of structural and useful kidney abnormalities in sufferers with diabetes. The structural abnormalities consist of hypertrophy of the kidney, growth in glomerular basement membrane thickness, nodular and diffuse glomerulosclerosis, tubular atrophy, and interstitial fibrosis [1-4]. Diabetic nephropathy is also recognized as Kimmelstiel Wilson Syndrome. Other mechanisms, along with glomerular high blood pressure with hyperfiltration, elevated superior glycation stop products, sorbitol and protein kinase $\mathrm{C}$ (PKC) pathway activation, increase elements and cytokines which include reworking increase factor- $\beta$ (TGF- $\beta$ ), and genetic susceptibility, were recognized as critical deteriorating elements, however the ideal mechanisms via which diabetic renal damage progresses continue to be to be resolved [5].

\section{Stages in DN}

There are 5 stages in DN are-

Stage 1: Renal or kidney functions are changed in this stage. The kidney increases in size, and it is accompanied by high filtration and priming rate.

Stage 2: The structure of kidney is changed for worse and patients pass protein in their urine after intense physical activity.

Stage 3: This stage comes after patients have suffered from diabetes for 5 to 15 years and their renal functions begin to decline.

Stage 4: This stage is known as Clinical Diabetic Nephropathy whose characteristic is large amount of proteinuria, more than 3.5 grams daily, along with Edema and high blood pressure.

Stage 5: It is called uremia and patient's condition is critical. They need to undergo dialysis and kidney transplant to sustain their life. Other therapy are : dialysis, osmotherapy [6].

\section{Incidence of DN}

The incidence of diabetes is growing globally and the most booms is anticipated to be in growing international locations like India. By the 12 months 2010, it turned into envisioned that almost 220 million human beings global have been diabetic. India is going through a prime fitness care burden because of the excessive incidence of kind 2 diabetes and there are indicators that this will boom in addition withinside the following couple of decades. Nearly $30 \%$ of continual renal disasters in India are because of diabetic nephropathy7. Nephropathy because of diabetes may be recognized very effortlessly and may be prevented. Increased incidence of diabetic nephropathy in South

*Corresponding Author: Dr. Lalita Bansal 
Asians Racial variations in the superiority of diabetic renal disorder was reported. Asian human beings have significantly $(\mathrm{p}<0.01)$ better incidence $(52.6 \%)$ of diabetic give up level renal disorder (ESRD) whilst in comparison with the Caucasians (36.2\%) [8].

The occurrence of diabetic nephropathy in type 2 diabetic subjects is reported to be 5-9\% [9]. The risk for cardiovascular disease (CVD) was 3 fold higher in South Indian NIDDM subjects with nephropathy when compared with their non-nephropathic counterparts [10]. Thus, in type 2 diabetes, many patients may not

\section{DIABETIC NEPHROPATHY}

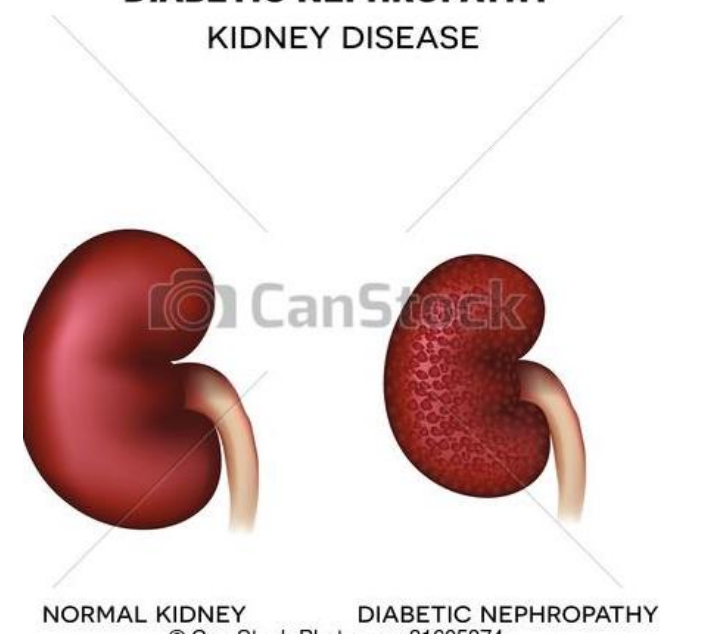

Fig-1: Diabetic Nephropathy from CVD. reach end stage renal disease due to premature death

\section{ETIOLOGY}

The precise reason is unknown however a few reasons are poor manage of blood sugar is idea to cause kidney harm. If there's additionally having excessive blood pressure, kidney harm is even greater likely, in a few instances own circle of relatives records may additionally play a role. Not everybody with diabetes develops this kidney problem, People with diabetes who smoke, and people with type- 1 diabetes additionally have better threat for kidney problems [11].

\section{Diabetes Affects the Kidney}

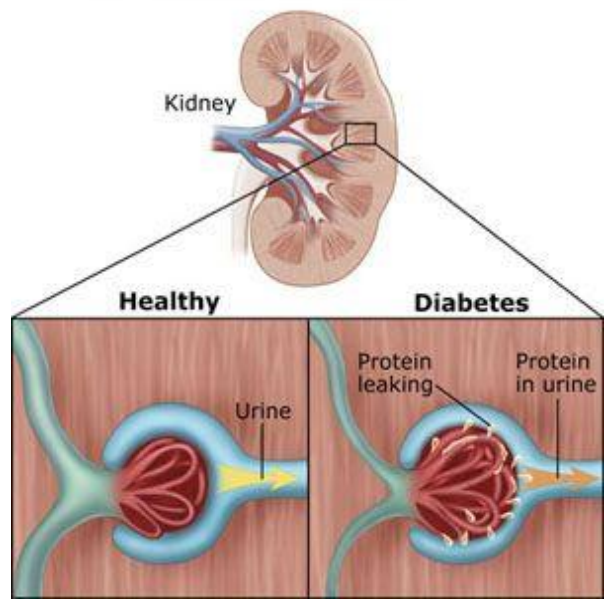

humans with T1DM withinside the first 10 years following diagnosis, however among 10 and 20 years the occurrence of $\mathrm{DN}$ is about $3 \%$ according to year. Overall, about $15 \%$ of humans with T1DM have severe (A3) albuminuria and a similarly $15 \%$ show moderate (A2) albuminuria. 2 After 20 years, the occurrence fee declines in order that humans with ordinary renal characteristic and ordinary urinary albumin excretion after 30 years of T1DM are at decrease danger of growing DN. eight Therefore, the danger of growing DN varies among people and depends now no longer best on length of T1DM, however it's also motivated through different factors, inclusive of glycaemic control, blood strain and genetic susceptibility [13].

\section{Molecular mechanism of Pathogenesis (DN)}

Recent observations imply that numerous pathways are activated at some stage in the improvement of diabetes mellitus; those pathways in my view or together modulate the induction and development of DN. Although the pathogenesis of DN is multifactorial, the mechanisms that propel its improvement continue to be in large part unclear. During the route of $\mathrm{DN}$, the purposeful derangement and structural transforming of the kidney, precipitated via way of means of hyperglycemic harm, are connected to adjustments in numerous cell occasions and activation of signaling pathways. These pathways 
engage in a cascade of complicated molecular mechanisms, ensuing withinside the most important pathogenic additives of $\mathrm{DN}$, which encompass renal fibrosis, mesangial enlargement, glomerular hypertrophy, oxidative strain, and tubular irritation. Some biomarkers are connected to those pathways. For instance, the renin-angiotensin-aldosterone machine is related to inflammatory cytokines along with tumor necrosis element $\alpha$ (TNF- $\alpha$ ) and interleukin (IL) $1 \beta$, whilst great proof shows that angiotensin II and aldosterone are most important mediators within side the pathogenesis of DN. Furthermore, the position of protein kinase $\mathrm{C}$ (PKC) withinside the induction and development of DN thru a complicated mechanism regarding its isoforms (PKC- $\alpha, \mathrm{PKC}-\beta$, and PKC- - ) has been properly reported. These isoforms were implicated as mediators of renal fibrosis and mesangial enlargement thru upregulation of vascular endothelial increase element (VEGF) expression in mesangial cells, in addition to reworking increase element- $\beta$ (TGF- $\beta$ ), kind IV collagen, laminin, and fibronectin withinside the glomeruli. Even as hyperglycemia-precipitated expression of a few NADPH oxidase subunits in mesangial cells happens in a PKC-established fashion, NADPH oxidase-pushed renal oxidative strain stimulates mesangial enlargement and albuminuria via way of means of growing the expression of fibronectin and collagen- 1 within side the kidney, TGF- $\beta 1$ being the main "fibrogenic" cytokine in vivo. Finally, inflammatory cytokines along with TNF- $\alpha$, IL-1, IL-6, and IL-18 are all concerned within side the improvement and development of $\mathrm{DN}$, as irritation additionally performs a vital position within side the process. Remarkably, expanded degrees of circulating TNF receptors in sufferers with T2DM were connected with development to ESKD whilst urinary TNF- $\alpha$ excretion has been related to severity of glomerular and tubulointerstitial harm in sufferers with T2DM [14-19].

\section{Management and Treatment of DN [20]}

GLYCEMIC CONTROL: Dipeptidyl-peptidase-4 inhibitors, Glucagon-like peptide-1 Receptor agonists, Metformin, Sodium-glucose cotransporter- 2 inhibitors and Thiazolidine-diones (e.g., pioglitazone).

BLOOD PRESSURE CONTROL: ACE inhibitors, Aldosterone antagonists and ARBs (Angiotensin receptor blocker).

LIPID MANAGEMENT: Statin

DIETARY MODIFICATION: The diets include whole-grain carbohydrates, fiber, fresh fruits and vegetables, omega-3 and omega-9 fats, and less than 2,300 mg per day of sodium. Foods that are high in sugar, saturated fats, and processed carbohydrates should be avoided.

Mineralocorticoid Receptor Antagonists

Endothelin Receptor Antagonists

Vitamin D Receptor Activators (VDRA)

Therapies Targeting Inflammation

Therapies Targeting Free Radicals (Resveratrol, Nrf2 Activators)

\section{Recent Potential Therapeutic Strategies [21]}

\section{Botanical effective in DN [22]}

Andrographis Paniculata (Family: Acanthaceae; Common name: Kalmegh)

Astragalus propinquus (Family: Fabaceae; Common name: Milk Vetch)

Benincasa cerifera (Family: Cucurbitaceae; Common name: Kusmanda)

Brassica oleracea (Family: Brassicaceae; Common name: Red Cabbage)

Camellia sinensis (Family: Theaceae; Common name: Green tea, Chaay)

Cinnamomum zeylanicum (Family: Lauracaeae; Common name: Dalchini)

Curcuma longa (Family: Zingiberaceae; Common name: Turmeric)

Dietary fish oil

Ganoderma lucidum (Family: Ganodermataceae; Common name: Lingzhi Mushroom).

Ginkgo biloba (Family: Ginkgoaceae; Common name: Maidenhair Tree)

Glycine max (Family: Fabaceae; Common name: Soyabean)

Gymnema montanum (Family: Asclepidaceae; Common name: Bidaria Tingens Deche)

Indigofera tinctoria Leaves (Family: Fabaceae; Common name: True Indigo) 


\section{Prevention measures DN}

- Keep blood sugar beneath control

- Maintain blood pressure in a normal range

- Consume less salt, less meat, and less saturated fats. Set a dietary plan and follow it.

- Exercise regularly

- Maintain a healthy weight

- Avoid smoking

- Avoid alcohol or limit alcohol intake

\section{CONCLUSION}

Diabetes mellitus is metabolic disorder related with structural and functional alterations of various organs system \& diabetic complications are associated with macrovascular and microvascular damage to the major organs of the body. Nephropathy is leading difficulty of Diabetes (DM) that affects about $40 \%$ of diabetics. It needs intense management, such as dialysis and may lead to renal transplant and badly affects superiority of life. The present review deal with brief about DN pathophysiology, prevention measures along with treatment approaches aided by allopathic as well as herbalism.

\section{REFERENCE}

1. Soni, H., \& Singhai, A. K. (2012). A recent update of botanicals for wound healing activity. International Research Journal of Pharmacy, 3(7), 1-7.

2. Reeves, W. B., \& Andreoli, T. E. (2000). Transforming growth factor $\beta$ contributes to progressive diabetic nephropathy. Proceedings of the National Academy of Sciences, 97(14), 7667-7669.

3. Alebiosu, C. O., Kadiri, S., \& Akang, E. E. U. (2002). Clinicopathological study of diabetic nephropathy based on renal biopsy. Diabetes International, 12, 669.

4. Kimmelstiel, P., \& Wilson, C. (1936). Intercapillary lesions in the glomeruli of the kidney. The American journal of pathology, 12(1), 83.

5. Mauer, S. M., Steffes, M. W., Ellis, E. N., Sutherland, D. E., Brown, D. M., \& Goetz, F. C. (1984). Structural-functional relationships in diabetic nephropathy. The Journal of clinical investigation, 74(4), 1143-1155.

6. Parving, H. H., Osterby, R., \& Ritz, E. (2000). Diabetic nephropathy. The Kidney. Brenner BM.

7. Agarwal, S. K., \& Dash, S. C. (2000). Spectrum of renal diseases in Indian adults. The Journal of the Association of Physicians of India, 48(6), 594-600.

8. Young, B. A., Maynard, C., \& Boyko, E. J. (2003). Racial differences in diabetic nephropathy, cardiovascular disease, and mortality in a national population of veterans. Diabetes care, 26(8), 23922399.

9. John, L., Rao, P. S., \& Kanagasabapathy, A. S. (1991). Prevalence of diabetic nephropathy in non- insulin dependent diabetics. The Indian journal of medical research, 94, 24-29.

10. Adler, A. I., Stevens, R. J., Manley, S. E., Bilous, R. W., Cull, C. A., Holman, R. R., \& UKPDS Group. (2003). Development and progression of nephropathy in type 2 diabetes: the United Kingdom Prospective Diabetes Study (UKPDS 64). Kidney international, 63(1), 225-232.

11. Inzucchi, S.E., Sherwin, R.S., Goldman, L., Ausiello, D. (2007). Diabetes Mellitus. Cecil Textbook of Medicine, 23; chap 248.

12. Parving, H. H., Osterby, R., \& Ritz, E. (2000). Diabetic nephropathy. The Kidney. Brenner BM.

13. Parving, H. H., Hommel, E., Mathiesen, E., Skøtt, P., Edsberg, B., Bahnsen, M., ... \& Lauritzen, E. (1988). Prevalence of microalbuminuria, arterial hypertension, retinopathy, and neuropathy in patients with insulin dependent diabetes. Br Med J (Clin Res Ed), 296(6616), 156-160.

14. Arora, M. K., \& Singh, U. K. (2013). Molecular mechanisms in the pathogenesis of diabetic nephropathy: an update. Vascular pharmacology, 58(4), 259-271.

15. Wada, J., \& Makino, H. (2013). Inflammation and the pathogenesis of diabetic nephropathy. Clinical science, 124(3), 139-152.

16. Tavridou, A., Georgoulidou, A., Roumeliotis, A., Roumeliotis, S., Giannakopoulou, E., Papanas, N., ... \& Vargemezis, V. (2015). Association of plasma adiponectin and oxidized low-density lipoprotein with carotid intima-media thickness in diabetic nephropathy. Journal of Diabetes Research, 2015.

17. Koya, D., Jirousek, M. R., Lin, Y. W., Ishii, H., Kuboki, K., \& King, G. L. (1997). Characterization of protein kinase $\mathrm{C}$ beta isoform activation on the gene expression of transforming growth factor-beta, extracellular matrix components, and prostanoids in the glomeruli of diabetic rats. The Journal of clinical investigation, 100(1), 115-126.

18. Asaba, K., Tojo, A., Onozato, M. L., Goto, A., Quinn, M. T., Fujita, T., \& Wilcox, C. S. (2005). Effects of NADPH oxidase inhibitor in diabetic nephropathy. Kidney international, 67(5), 1890-1898.

19. Zugmaier, G., Paik, S., Wilding, G., Knabbe, C., Bano, M., Lupu, R., ... \& Lippman, M. (1991). Transforming growth factor $\beta 1$ induces cachexia and systemic fibrosis without an antitumor effect in nude mice. Cancer research, 51(13), 3590-3594.

20. McGrath, K., \& Edi, R. (2019). Diabetic kidney disease: diagnosis, treatment, and prevention. American family physician, 99(12), 751759.

21. Samsu, N. (2021). Diabetic nephropathy: challenges in pathogenesis, diagnosis, and treatment. BioMed Research International, 2021.

22. Samsu, N. (2021). Diabetic nephropathy: challenges in pathogenesis, diagnosis, and treatment. BioMed Research International, 2021.

Cite This Article: Lalita Bansal \& Ashish Dhiman (2022). A Rationalized Overview of Diabetic Nephropathy. East African Scholars J Med Surg, 4(1), 15-18. 